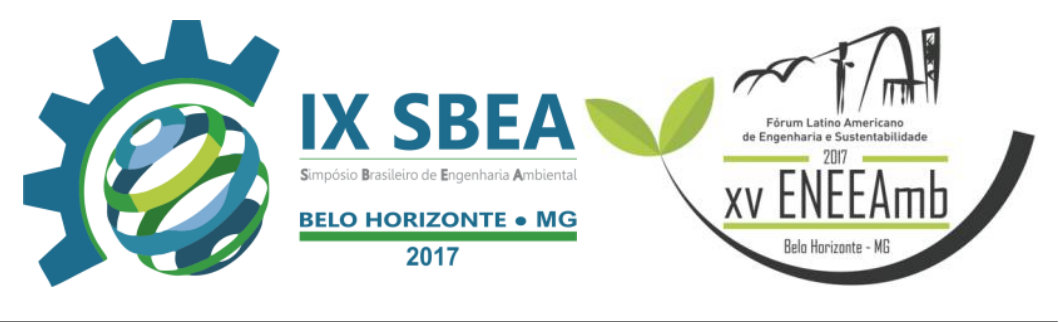

GESTÃO AMBIENTAL E POLÍTICAS PÚBLICAS

\title{
PARQUE MUNICIPAL SERRA DO PERIPERI: UM BREVE ESTUDO ACERCA DO (DES)CUMPRIMENTO DA LEGISLAÇÃO AMBIENTAL APLICÁVEL
}

Marilia de Jesus Oliveira-marilia.oliveira.vdc@ hotmail.com IFBA - Instituto Federal de Educação, Ciência e Tecnologia da Bahia Adonias de Lima Souza - adonias.lima@ hotmail.com IFBA - Instituto Federal de Educação, Ciência e Tecnologia da Bahia

Gislane Nunes de Andrade - anny.nandrade@gmail.com IFBA - Instituto Federal de Educação, Ciência e Tecnologia da Bahia Jeferson Santos Barros - mjefersonchaos@ hotmail.com UFSC - Universidade Federal de Santa Catarina

Mariana Oliveira de Jesus-mary_oliver_veira@hotmail.com FTC - Faculdade de Tecnologia e Ciências 


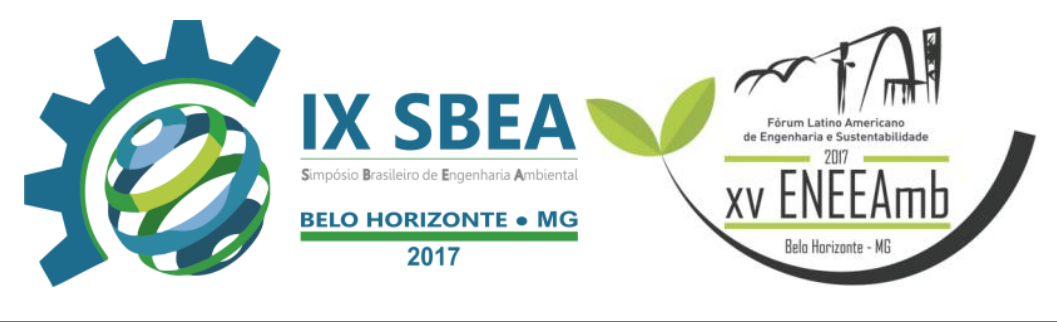

\section{RESUMO}

Esta pesquisa apresenta um estudo da aplicabilidade da legislação ambiental na Área de Proteção Permanente Parque Municipal Serra do Periperi (PMSP) e investiga a existência do avanço de edificações da construção civil sobre a área do parque. $\mathrm{O}$ objetivo é analisar no tocante as legislações aplicáveis ao PMSP quais estão possivelmente sendo descumpridas com uma escalada do perímetro urbano sobre a área da Unidade de Proteção Permanente (UPP). Para tanto a estratégia metodológica deste trabalho compreenderá visitas nos limites da área do PMSP, e identificação de possíveis edificações instaladas dentro do PMSP. Espera-se com isso sermos capazes de dar ciência a sociedade quanto a possível escalada da área urbana sobre a Unidade de Conservação (UC).

Palavras-chave: Construção Civil, Zona de Amortecimento, Legislação Ambiental.

\section{INTRODUÇÃO/OBJETIVO}

O processo de urbanização no Brasil tem se intensificado muito a partir das décadas de sessenta, onde a população urbana superou a rural (CORRÊA, 1970). Essa acelerada urbanização se deu pelo conjunto de mudanças ocorridas na economia, resultando numa intensa migração interna, dos quais perdura até os dias de hoje, com o crescimento de grandes e médias cidades, novas formas de produção, urbanização, industrialização são alguns dos fenômenos característicos desse processo de desenvolvimento no Brasil (FARIA, 1978).

Embora esse crescimento por um lado demonstre pontos positivos que é o crescimento econômico e melhoria de qualidade de vida, outra questão que muitas vezes é deixada em segundo plano é o convívio desse crescimento com área de proteção ambiental, a sociedade tem se tornado cada vez mais exploradora dos recursos naturais resultando intenso impacto sócio-ambiental (MENDONÇA, 2005).

O convívio de grandes concentrações de pessoas com área de preservação não tem sido harmonioso. Alguns estudos como Porto (2008) apontam que áreas urbanas têm avançado sobre área de vegetação nativa. Já Benedictis (2007) mostra que o descarte de resíduos sólidos é um grande problema, como despejo irregular de resíduos em locais de preservação e falta de educação ambiental.

Campos (2004) em seu estudo aborda sobre o grande desmatamento que vem ocorrendo em áreas de cerrado, em virtude ao aumento de produção de monoculturas nessas áreas, e também relata sobre a forte degradação no Parque Ecológico de 


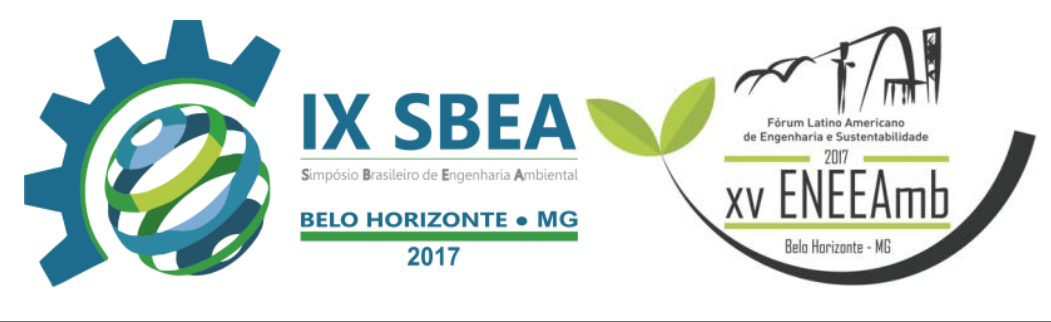

Preservação Ambiental na cidade de Goiânia, área que segundo o autor era rica em vegetação de cerrado, hoje em consequência da crescente urbanização no seu entorno, se encontra em grande parte desmatado. Poluição de rio e morte de nascentes são também efeitos associados a grandes concentrações urbanas, falta de conscientização e envolvimento da população com as questões ambientais (ROCHA, 2007).

No contexto deste trabalho, a Unidade de Conservação (UC) do Parque Municipal Serra do Periperi (PMSP), localizada na cidade de Vitória da Conquista estado da Bahia, se constitui como um objeto de estudo, o qual se enquadra no cenário de crescimento e convívio UCs expostos acima.

Vitória da Conquista destaca com um dos índices mais acelerado de crescimento demográfico e desenvolvimento urbano do Estado da Bahia, é um dos mais elevados do Norte e Nordeste. De acordo dados obtido no site Prefeitura Municipal de Vitória da Conquista PMVC, a população flutuante de Vitória da Conquista (não residentes) é cerca de $30 \%$ do total de 346.069 habitantes estimado para o ano de 2016, esse dado confirma sua posição de cidade-pólo onde o desenvolvimento da região é uma constante.

Desse modo, num contexto ambiental é uma cidade peculiar, a qual possui grande diversidade em sua flora e fauna, por estar situada em uma área de tensão ecológica contendo em si uma mistura dos biomas, Caatinga, Cerrada e Mata Atlântica (AMARAL, 2012). Além disso, assume relevância quanto de natureza hídrica fazendo parte uma região berçário de nascentes de rios.

Segundo Benedictis (2007, p. 16): “a população mais carente tem avançado para áreas que são em sua maioria consideradas de preservação ambiental e de risco sem nenhuma infra-estrutura". Com isso, apresenta o caso da Serra do Periperi, que é área de preservação ambiental permanente.

Com base nesse entendimento, ato recente e muito repercutido em redes sociais, foi a ocupação de áreas verdes dentro do PMSP, local situado na área de acesso do Anel Viário ao Loteamento Nova Cidade, essa invasão foi realizada de forma irregular por pessoas de baixa renda que alegavam não ter residências, isso durou cerca de seis meses e foi o suficiente para desmatar toda a vegetação que havia naquela área, esses problemas sociais infelizmente acabam afetando diretamente as Áreas de Proteção 


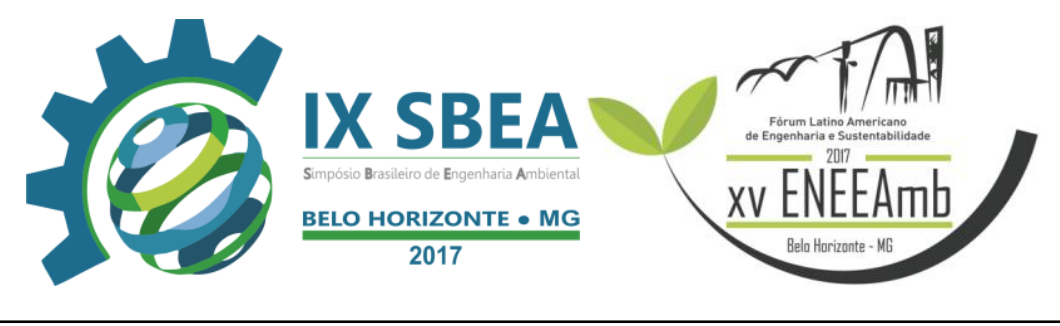

Ambiental (APA), após o conhecimento das invasões pelos órgãos competentes, esses fizeram a retirada das famílias informando que seriam remanejadas para casas sociais.

\section{METODOLOGIA}

\subsection{Local e Objeto do Estudo}

O Parque Municipal Serra do Periperi foi criado pelo decreto municipal $n^{\circ}$ 9.480/99 com objetivo de proteger o bioma local e os recursos hídricos, se enquadra como uma área de proteção integral, no entanto o processo de criação do parque foi gradativo conforme descritos por Estevam, Santos e Brito (2005) inicialmente, em 1996 com decreto 8.695/96 foi declarada como área preservada 500 hectares, proibindo a extração mineral e o desmatamento. Logo após em 1998 a área dobrou de tamanho, com a intenção de coibir ações predatórias. Em 1999 o parque foi instituído e teve sua área ampliada para 1.300 hectares. Abaixo mapa do PMSP atualmente.

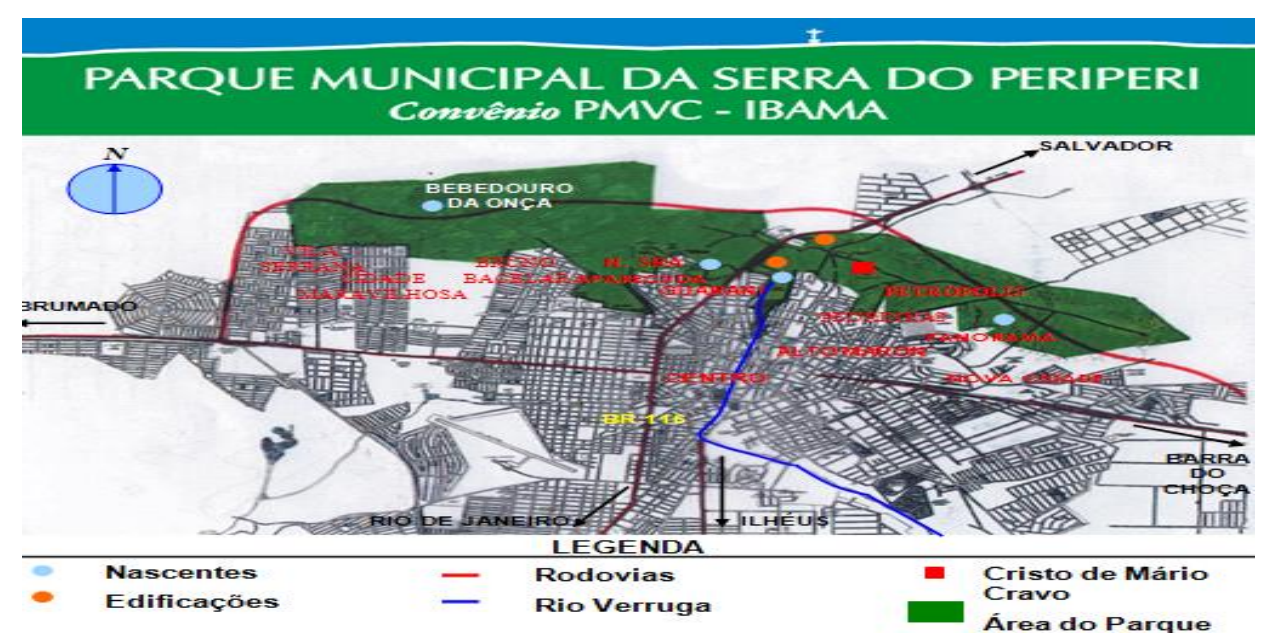

Figura 1. Mapa do PMSP

Fonte: Plano de Manejo/2007.

\subsection{Legislações aplicáveis ao Parque Municipal Serra do Periperi}

No ano de 1972 ocorreu a Conferência de Estocolmo que teve como objetivo destacar a importância da conscientização da sociedade para com o meio ambiente, visando melhorar a relação homem versus meio ambiente evitando o comprometimento 


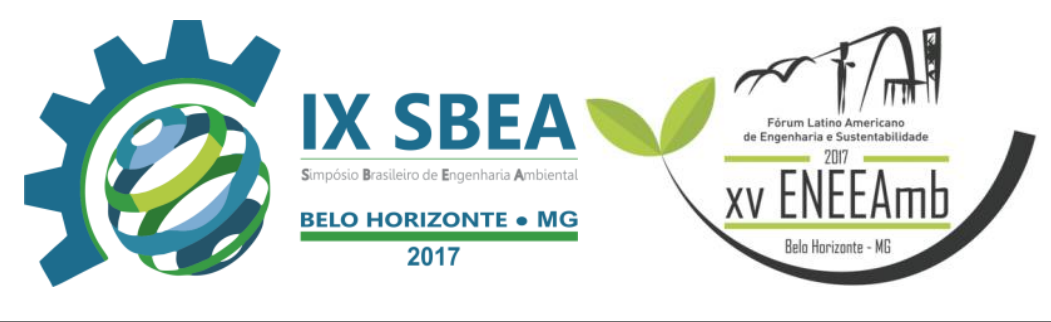

as gerações futuras, a partir desse período cresceu o surgimento de leis para amparar os efeitos destruidores com o meio ambiente (MACHADO, 2006).

A lei federal $n^{\circ} 4.771 / 65$ é responsável pelo Código Florestal e pela criação de parques, reservas florestais nacionais, estaduais e municipais; lei 5.197/67 trata sobre a proteção a fauna e criação de reservas biológicas nacionais, estaduais e municipais; lei 6.513/77 aborda a criação de áreas especiais e de locais turísticos; lei 6.938/81 dispõe sobre a Política Nacional do Meio Ambiente (PNMA) abordando sobre o funcionamento e aplicação em relação à criação de espaços territoriais especialmente protegidos pelos poderes público, federal, estadual e municipal, tais como: áreas de proteção ambiental, reservas extrativistas, além da transformação de determinadas áreas em reservas ou estações ecológicas.

A lei 12.305/10 institui a Política Nacional de Resíduos Sólidos (PNRS) aborda sobre os principais problemas ambientais decorrente ao manejo inadequado dos resíduos sólidos.

Para conservação das Unidades de Conservação (UC), com o intuito de proteger e preservar essas unidades, foi criado o Sistema Nacional de Unidade de Conservação (SNUC) pela lei 9.985, de 18 de julho de 2000, esse sistema atua em três esferas do governo, municipal, estadual e federal, com o objetivo de harmonizar a relação entre estado, cidadão e o meio ambiente.

Esse sistema supracitado é gerido pelo Conselho Nacional do Meio Ambiente CONAMA, órgão consultivo e deliberativo, com as atribuições de acompanhar a implementação do conjunto. No art. 27 da lei do SNUC abordam sobre a necessidade de todas as UCs disporem do Plano de Manejo, esse deve abranger a área da unidade de conservação, sua zona de amortecimento e os corredores ecológicos para UC recém criada, e deve ser elaborado no prazo de cinco anos a partir da data de sua criação. São proibidas quaisquer alterações, atividades ou modalidades de utilização em desacordo com os seus objetivos.

Em relação a Zona de Amortecimento, foi criada pelo artigo $2^{\circ}$, da lei do SNUC, que estabelece limite da zona de amortecimento de uma Unidade de Conservação (UC), a fim proteger e minimizar impactos negativos diante da expansão da atividade humana 


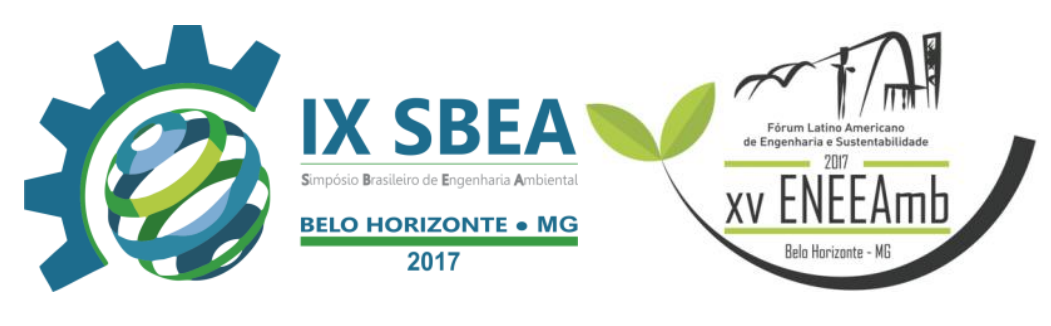

nessas áreas e contribuir para a manutenção da estabilidade, equilíbrio do ecossistema garantindo a integridade da área protegida.

Contudo, o Sistema Nacional de Unidade de Conservação (SNUC) agrupa a Unidade de Conservação (UC), em dois grandes grupos, temos a UC de proteção integral e UC de uso sustentável, sendo o Parque Municipal Serra do Periperi (PMSP), classificado como unidade de proteção integral, área pública, não sendo permitido seu uso direto, população residente, visitação apenas permitida sob normas e restrições (PLANO DE MANEJO, 2007).

Já as UC de uso sustentável são possíveis utilizar os espaços rurais e exploração dos recursos desde que realizado de forma sustentável e dentro do que dita a lei ambiental.

\section{RESULTADOS E DISCUSSÃO}

Foram selecionadas algumas áreas para realizar a visita e fazer registros fotográficos, limites do bairro Nova Cidade com o Parque Municipal Serra do Periperi (PMSP) área que foi bastante degradada devido a recente invasão, limites do parque com o Condomínio Nova Cidade e limites do parque com os bairros Guarani e Cruzeiro. A partir das coordenadas coletadas latitude e longitude foram inseridas no Google Maps a fim de fazer sua localização. Ao percorrer pelas estradas do parque foi possível avistar também inúmeros pontos de descartes irregulares de resíduos sólidos, grande parte desses resíduos é oriunda de matérias de construção civil e resíduos domésticos, abaixo localização das áreas que fazem limite com o PMSP e os pontos de descartes irregulares. 

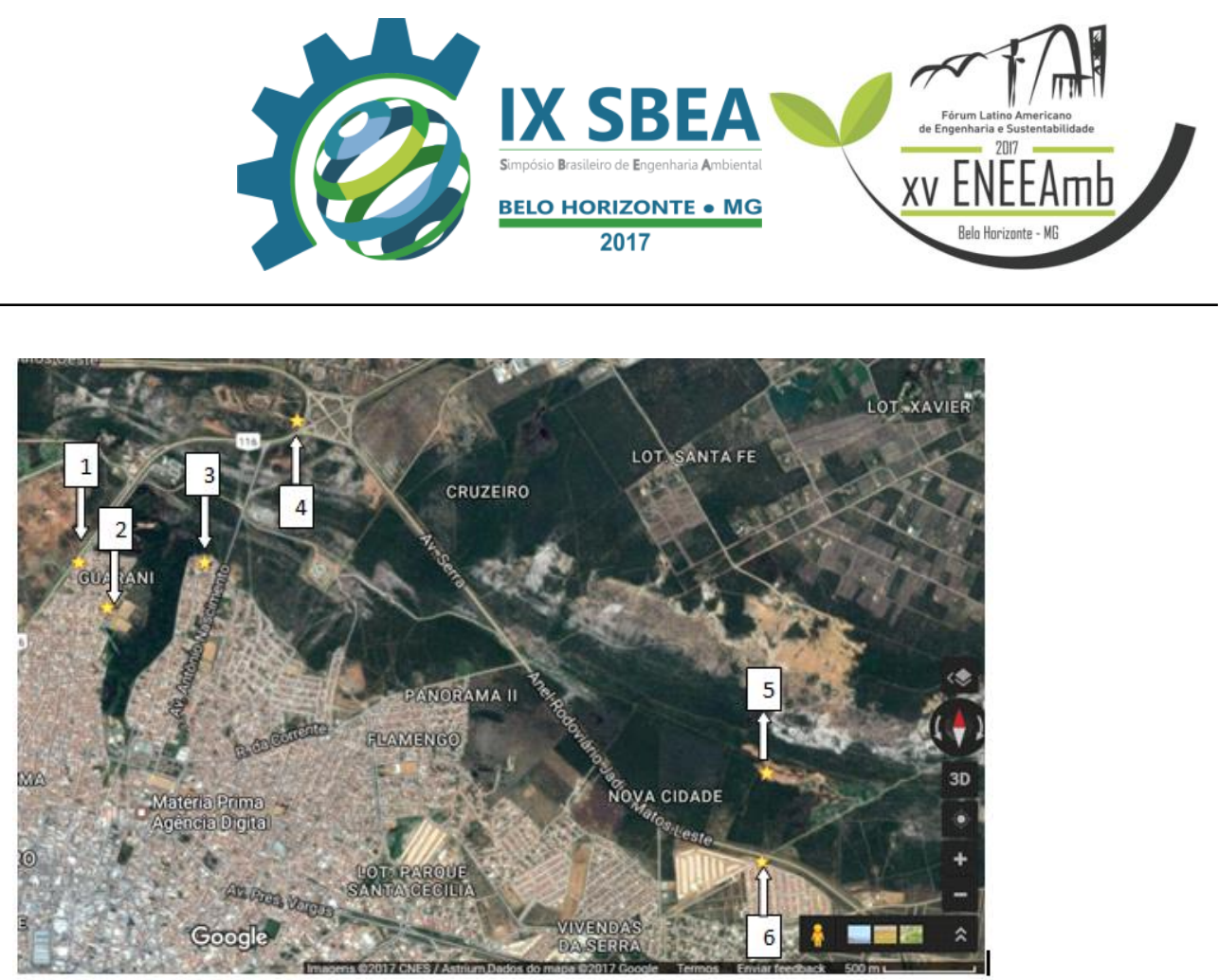

Figura 2. Localização das áreas visitadas Fonte: Autor do trabalho, (2017).

Ponto 1: Zona de limite do PMSP com o bairro Guarani, área bastante degradada devido a forte pressão urbana.

Ponto 2: Área de Proteção Ambiental (APA) sendo utilizada como descarte de resíduos sólidos pelos moradores do bairro Cruzeiro.

Ponto 3: Registro de edificação nas limitações do PMSP.

Ponto 4: Via de acesso ao bairro Cruzeiro, foram encontrados vários pontos de descarte irregular de resíduos sólidos na APA.

Ponto 5: Limites do bairro Nova Cidade com o parque, local onde ocorreu invasão na APA.

Ponto 6: Condomínio no bairro Nova Cidade, esse se faz suspeito devido está localizado nos limites do parque.

Abaixo as imagens coletadas dos locais que fazem limites com a zona de amortecimento do PMSP e que também apresenta descarte irregular de resíduos sólidos pelos moradores. 

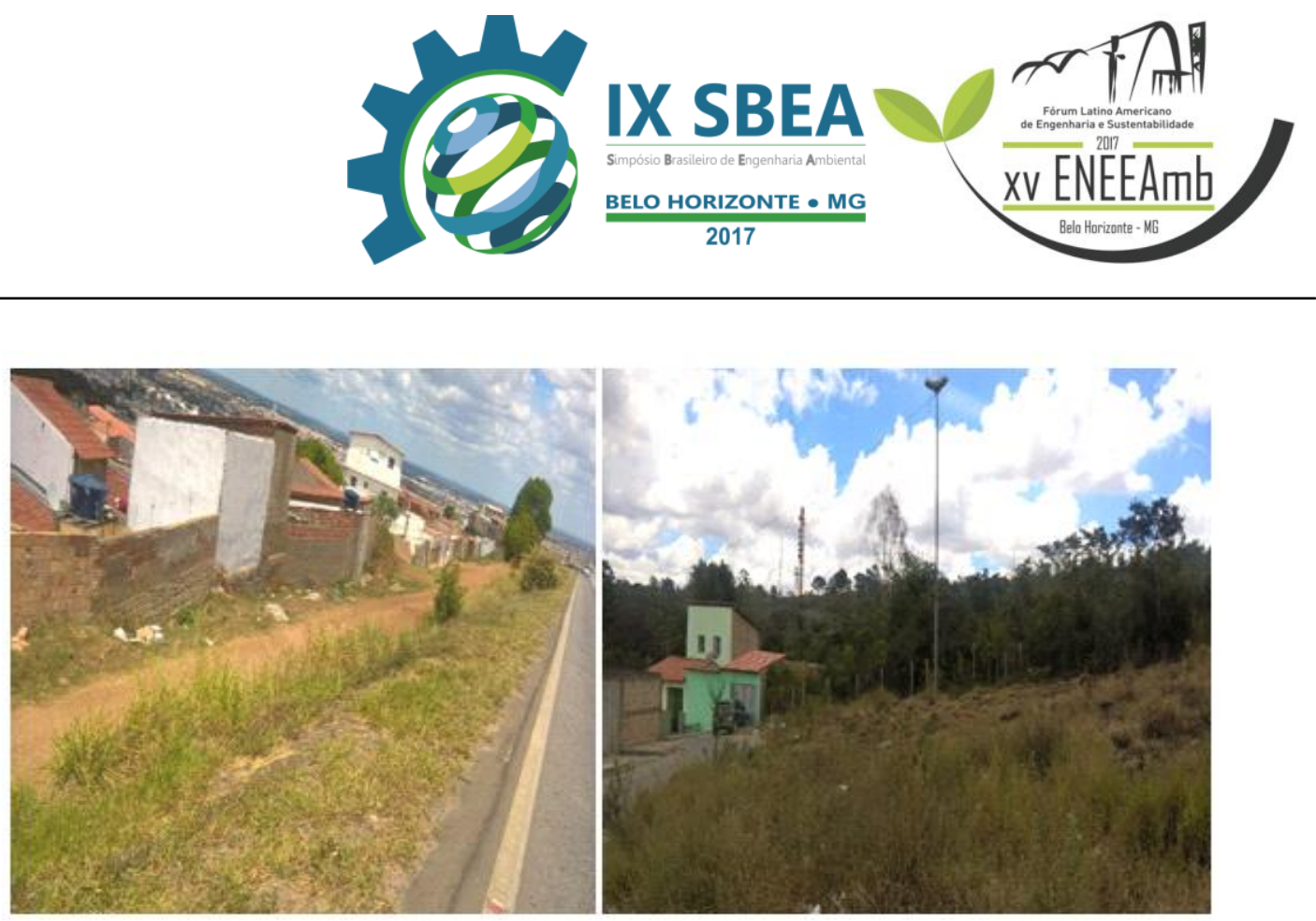

Figura 3 - Registro fotográfico, a direita limite do PMSP com o bairro Guarani, a esquerda limite do parque com o bairro Cruzeiro.

Fonte: Autor do trabalho, (2017).

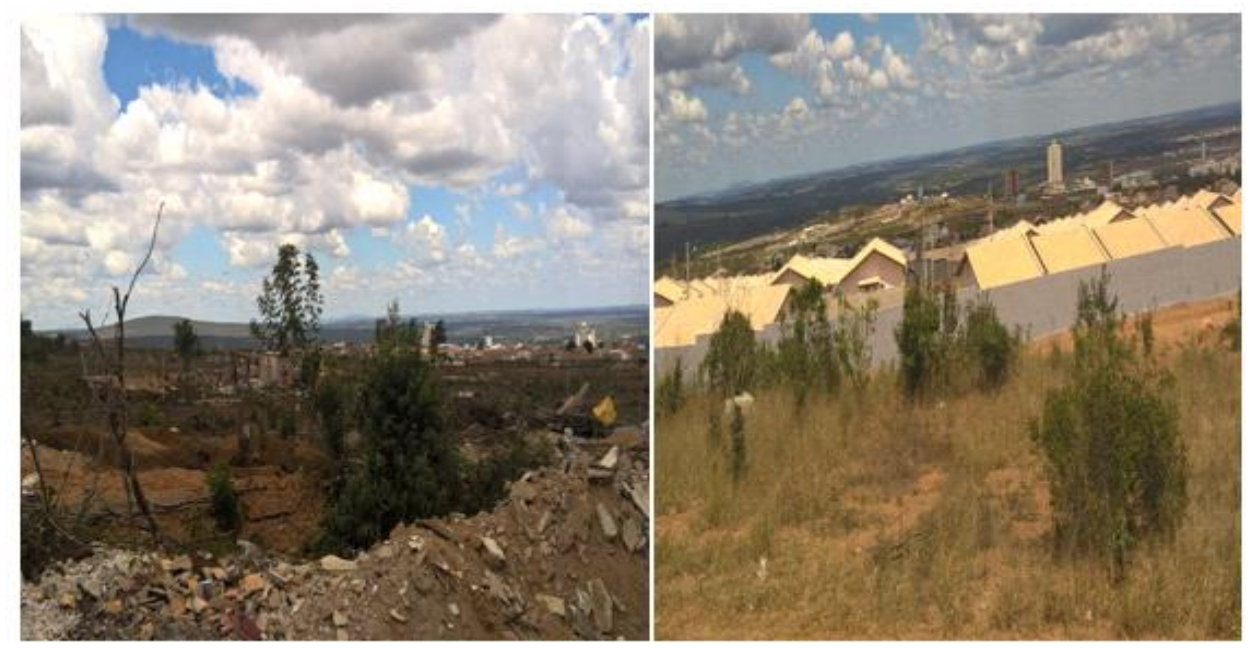

Figura 4. Registro fotográfico, a direita limite do PMSP onde foi realizada a invasão, a esquerda limite do parque com o Condomínio Nova Cidade.

Fonte: Autor do trabalho, (2017). 

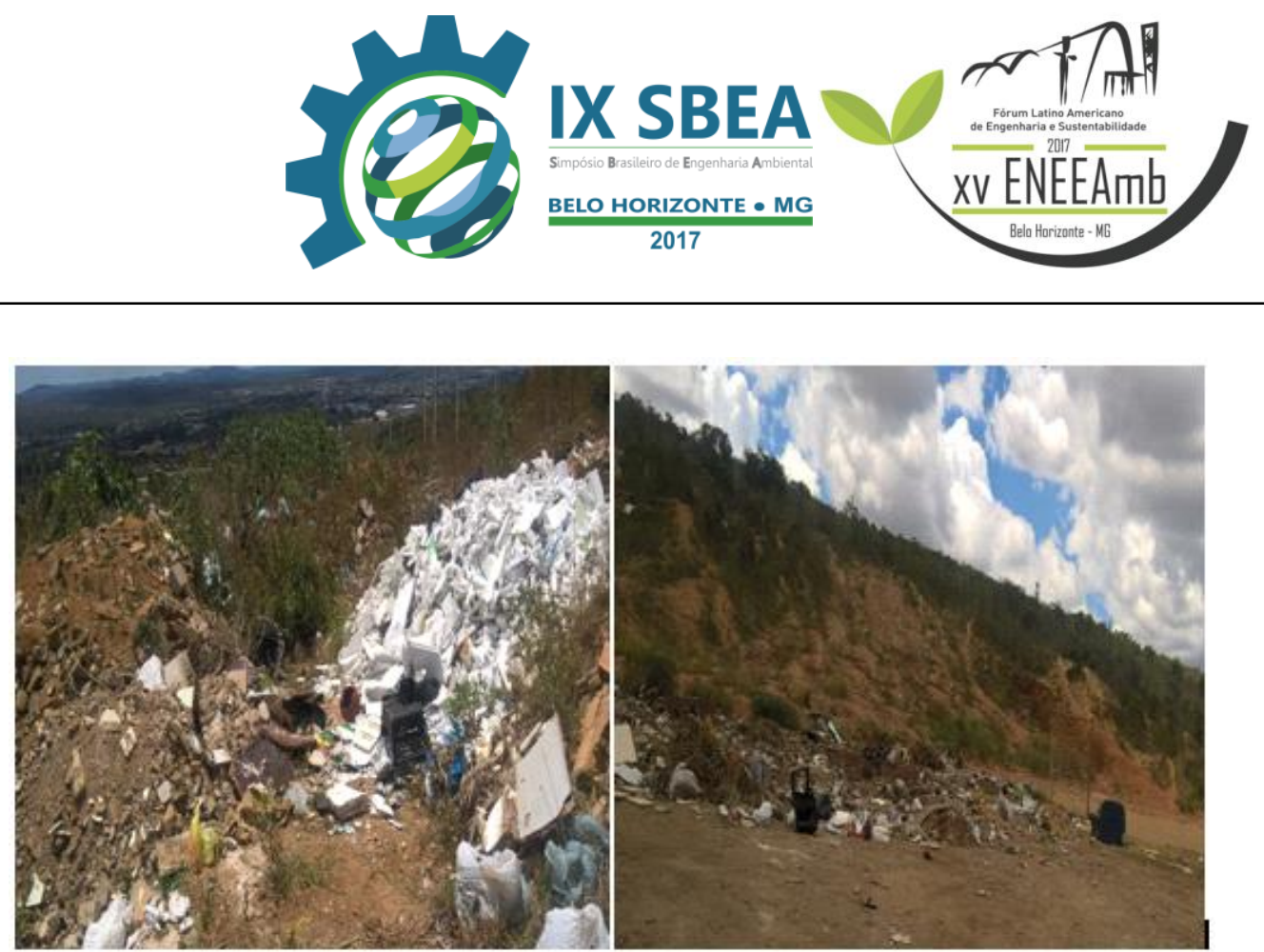

Figura 5. Registro fotográfico, à direita e esquerda limite do PMSP com o Bairro Cruzeiro. Fonte: Autor do trabalho, (2017).

\section{CONCLUSÕES/RECOMENDAÇÕES}

Apesar de haver leis e sistema que gerencie os princípios de conservação como o Sistema Nacional de Unidade de Conservação (SNUC) a fim de promover e recuperar matas nativas como é o caso da Unidade de Conservação (UC), na sua maioria são ineficazes. A Secretaria de Meio Ambiente (SEMMA), setor público responsável pela gestão do Parque Municipal Serra do Periperi são tecnicamente frágeis, sendo mais corretivo que preventivo, agindo mediante aos danos já causados ao parque. Motivo pelo qual a invasão na Área de Proteção Ambiental (APA) durou cerca de seis meses, resultou uma grande devastação, só após o ocorrido que o órgão responsável tomou as devidas providências.

Outro problema enfrentado pelo PMSP é o descarte de resíduos sólidos dentro do parque, essa atividade é uma agressão a lei 12.305/10 do Plano Nacional de Resíduos Sólidos (PNRS) indo de contra ao correto manejo dos resíduos sólidos.

No mais, é possível afirmar o conhecimento dos reflexos nocivos potencialmente degradador diante da expansão urbana nas Áreas de Preservação Ambiental (APA).

Recomenda-se para trabalhos futuros a elaboração de um georreferenciamento para identificar as suspeitas levantadas nesse trabalho.

\section{REFERÊNCIAS BIBLIOGRÁFICAS}




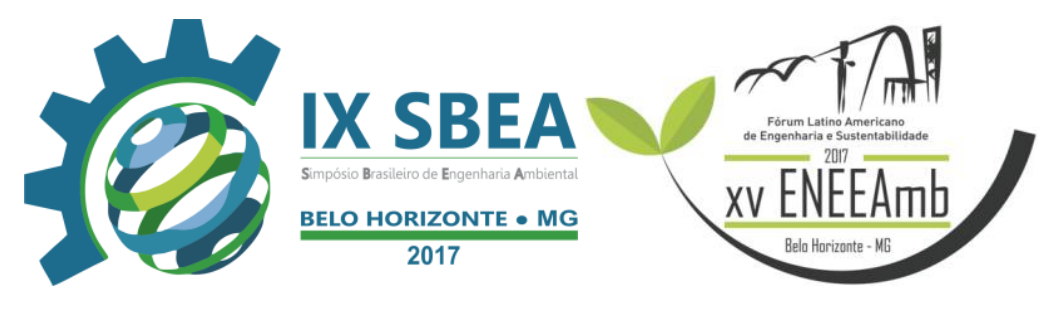

AMARAl, U. T. Pressões do Crescimento Urbano da Cidade de Vitória da Conquista sobre o Parque Municipal da Serra do Periperi. Trabalho de Conclusão de Curso - Graduação em Geografia - Universidade Estadual do Sudoeste da Bahia UESB, 2012.

BENEDICTIS, N. M. S. M. Política ambiental e desenvolvimento urbano na serra do periperi em Vitória da Conquista - BA. Dissertação de Mestrado. Natal - RN. UFRN, 2007

CORREAA, R. L. Cidade e Região no Sudoeste Paranaense. Revista Brasileira de Geografia. v. 32, n. 2, p. 3-155, 1970.

ESTEVAM, A.L.D.; SANTOS, E.A. dos.; BRITO, M. da S. Depósitos tecnogênicos Quinários no interior baiano: $O$ caso da lavra de sedimentos no Parque da Serra do Periperi - Região Sudoeste da Bahia. In: CONGRESSO BRASILEIRO DE ESTUDOS DO QUATERNÁRIO, ENCONTRO BRASILEIRO DO TECNÓGENO, 2005, Guarapari.

FARIA, V. A. Conjuntura social brasileira: Dilemas e perspectivas. Novos Estudos Cebrap, São Paulo, n. 33, 1992.

INSTRUÇÕES NORMATIVAS DO MMA - Restauração e Preservação de Áreas de Preservação Permanente-APP: Dispositivos que tratam de Áreas de Preservação Permanente (APP) na legislação brasileira vigente, 2002.

MACHADO, A. A. Ambiental internacional: A construção social ampliada. Rio de Janeiro, vol. 28, no 1, junho 2006, p. 7-51.

MENDONÇA, R. Conservar e criar: Natureza, cultura e complexidade. Editora Senac São Paulo. São Paulo, 2005.

PLANO DE MANEJO. Unidade Gestora: Secretaria Municipal do Meio Ambiente, Vitória da Conquista- Bahia. 2007.

Prefeitura Municipal de Vitória da Conquista (PMVC). Disponível em: http://www.pmvc.ba.gov.br/governo-municipal-crescimento-urbano-da-cidadepoloeducacional-destacque-sudoeste. Acesso em: 18/02/2017.

PORTO, A. C. Degradação Ambiental em Unidades de Conservação Estaduais: Dissertação de Mestrado em Geografia do Instituto de Estudos Sócio-Ambientais da Universidade Federal de Goiás. 2004.

PORTO F. M. Legislação e Políticas Públicas Ambientais: Experiência do Parque Municipal da Serra do Periperi no Município de Vitória da Conquista. Dissertação de Mestrado, UESC. 2008. 


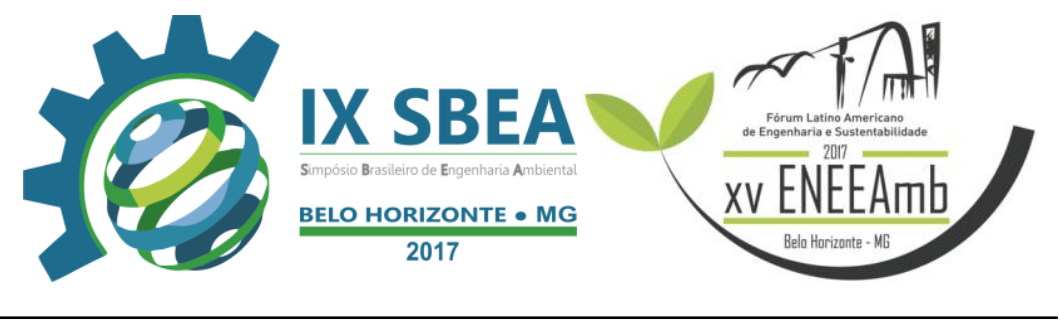

ROCHA, A. A. Analise Socioambiental da bacia do Rio Verruga os Processos da Urbanização de Vitória da Conquista - Ba. Dissertação de Mestrado, UFPB. 2008.

SILVA, I. S. da. A Serra do Periperi e as Implicações Socioambientais Decorrente da Expansão Urbana di Vitória da Conquista- Ba. Dissertação de Mestrado, UFSE. 2013.

CAMPOS, A. C. O Caso do Parque Ecológico Altamiro de Moura Pacheco e seu Entorno. Dissertação de Mestrado, UESC. 2008. 